\title{
Implementing Collaborative Projects Using a National Academy of Engineer- ing (NAE) Grand Challenge: Provide Access to Clean Water.
}

\section{Dr. Kamau Wright, University of Hartford}

Kamau Wright is an assistant professor of mechanical engineering at the University of Hartford. He specializes in thermo-fluids and plasma engineering. His technical research interests include applications of high voltage plasma discharges to liquids and wastewaters; fouling prevention and mitigation for heat exchangers; oxidation of organic matter in water; and inactivation of bacteria using high voltage plasmas.

\section{Dr. Ivana Milanovic, University of Hartford}

Prof. Milanovic is a professor of the mechanical engineering at the University of Hartford. Her area of expertise is thermo-fluids with research interests in vortical flows, computational fluid dynamics, multiphysics modeling, and collaborative learning strategies. Prof. Milanovic is a contributing author for more than 80 journal publications, NASA reports, conference papers and software releases. Dr. Milanovic is elected member of the Connecticut Academy of Science and Engineering, and her honors include six NASA Faculty Fellowship Awards, The Bent Award for Scholarly Creativity, Award for Innovations in Teaching and Learning, and Outstanding Teacher Award of the University of Hartford.

\section{Dr. Tom A. Eppes, University of Hartford}

Professor of Electrical \& Computer Engineering University of Hartford 200 Bloomfield Ave. West Hartford, Ct 96117

Ph.D. Electrical Engineering, University of Michigan MSEE, BSEE, Texas A\&M University 


\title{
Implementing Collaborative Projects Using a National Academy of Engineering (NAE) Grand Challenge: Provide Access to Clean Water
}

\begin{abstract}
A Collaborative Project (CP) was implemented as a High Impact Practice (HIP) by meeting criteria that included being embedded in a credit-bearing course, presenting students with a realworld problem, and counting for a significant percentage of the final grade. The purpose of this paper is to describe progress and impact of such a CP incorporated into a sophomore engineering course (Thermodynamics I) to enhance teaching and learning. Students were tasked with addressing one of the National Academy of Engineering (NAE) Grand Challenges: "Provide Access to Clean Water." Toward this goal, they were required to propose and analyze a design of a novel decentralized water treatment device. The analysis was additionally enhanced with a modeling and simulation component. Students were introduced to COMSOL Multiphysics® simulation software to improve their solutions and research experience. Overall, the CP effort resulted in increased understanding of the material and interest in research. The later included presentations at the Undergraduate Research \& Creativity Colloquium. Assessment was based on students' (1) work; (2) peer evaluations using Comprehensive Assessment of Team-Member Effectiveness (CATME), a web-based tool; (3) surveys during the CP experience; and (4) surveys in post-requisite courses. The comparison of these assessments provides cross-sectional and semi-longitudinal results. Cross-sectional results obtained in post-requisite courses indicated that CP students in comparison with non-CP students, typically had a higher level of agreement that they understood thermodynamics; had built professional camaraderie with some of their engineering classmates in thermodynamics; were excited to do undergraduate research; and were interested in further using modeling and simulation software.
\end{abstract}

\section{Introduction}

This study reports on an effort to enhance teaching and learning by implementing a $\mathrm{CP}$, HIP learning strategy [1], in sophomore engineering courses. The CP was developed and implemented in select Thermodynamics I (ME 236) sections in spring 2017, using one of the National Academy of Engineering (NAE) Grand Challenges: "Provide Access to Clean Water" [2]. This paper will address development, implementation, and assessment of a clean waterbased $\mathrm{CP}$.

The NAE Grand Challenges outline major engineering goals for the $21^{\text {st }}$ century, without directly endorsing any specific approach in a particular field. Challenges help identify engineering efforts which will positively impact people in the near future. For the present study, students were given an opportunity to develop solutions to one of these real-world problems, utilizing thermodynamic analysis and simulation tools. Table 1 shows the anatomy of this study, and outlines potential options for other studies, based on the premise of pairing a Grand Challenge with an appropriate engineering course, and associated engineering device/system/technology. 
TABLE 1

STUDY ELEMENTS AND OPTIONS

\begin{tabular}{|c|c|c|}
\hline & THIS STUdY & OPTIONS \\
\hline $\begin{array}{l}\text { NAE GRAND } \\
\text { CHALLENGE }\end{array}$ & $\begin{array}{l}\text { Provide Access to Clean } \\
\text { Water }\end{array}$ & $\begin{array}{l}\text { - Make Solar Energy Economical } \\
\text { - } \text { Provide Energy from Fusion } \\
\text { - } \text { Mevelop Carbon Sequestration Methods } \\
\text { - } \text { Restore and Improve Urban Infrastructure } \\
\text { - } \text { Advance Health Informatics } \\
\text { - } \text { Engineer Better Medicines } \\
\text { - } \text { Reverse-Engineer the Brain } \\
\text { - } \text { Secure Cyberspace } \\
\text { - } \text { Enhance Virtual Reality } \\
\text { - } \text { Advance Personalized Learning } \\
\text { Engineer the tools of Scientific Discovery }\end{array}$ \\
\hline Course & $\begin{array}{l}\text { Thermodynamics I } \\
\text { (ME 236) }\end{array}$ & $\begin{array}{l}\text { - Mechanical Engineering } \\
\text { - Civil Engineering } \\
\text { - Electrical Engineering } \\
\text { - Arts and Sciences } \\
\text { - Pre-medical fields } \\
\text { - Humanities }\end{array}$ \\
\hline $\begin{array}{l}\text { ENGINEERING } \\
\text { DEVICE/SYSTEM }\end{array}$ & $\begin{array}{l}\text { Novel decentralized } \\
\text { water treatment device } \\
\text { (preferably: Thermal } \\
\text { desalination system) }\end{array}$ & $\begin{array}{l}\text { (Selected based on professor's fields of study, } \\
\text { research, recommendation, etc.) }\end{array}$ \\
\hline $\begin{array}{l}\text { OPTIONAL USE OF } \\
\text { COMMERCIAL SOFTWARE }\end{array}$ & $\begin{array}{l}\text { COMSOL } \\
\text { Multiphysics }{ }^{\circledR} \text { Software }\end{array}$ & $\begin{array}{l}\text { COMSOL Multiphysics® Software } \\
\text { ANSYS }\end{array}$ \\
\hline
\end{tabular}

The lead author additionally decided to implement one of the HIPs: Collaborative Assignments and Projects. With the options described in Table 1, a matrix could be developed of most suitable pairings of Grand Challenges with courses in the undergraduate curriculum, for the purpose of implementing related CPs. This study coupled the Grand Challenge "Provide Access to Clean Water" with a 3-credit Thermodynamics I course, and focused on thermal desalination. The use of commercial software in the Grand Challenge is optional. However, the authors' intention was to introduce modeling and simulations early in the curriculum, help students gain valuable experience and start considering the use of modern tools and new skills in addressing engineering problems. Although students' ability to utilize COMSOL Multiphysics® (referred to as "COMSOL" throughout this text) for the final design would only be commensurate with their level of proficiency, understanding the capabilities of software packages in the specific project environment can better prepare them for future capstone projects, research experiences, and engineering practice [3]. 
CPs combine the two key goals of solving problems in the company of others, and sharpening individual understanding by listening seriously to the insights of others [1] . These goals are encompassed into University-specific HIP guidelines for a CP. These guidelines and corresponding course implementation are shown in Table 2.

\section{TABLE 2}

COLLABORATIVE PROJECTS: HIP CRITERIA AND IMPLEMENTATION

\begin{tabular}{|l|l|}
\hline \multicolumn{2}{|c|}{ COLLABORATIVE PROJECTS } \\
\hline \multicolumn{1}{|c|}{ UNIVERSITY HIP GUIDELINES } & \multicolumn{1}{c|}{ COURSE IMPLEMENTATION } \\
\hline $\begin{array}{l}\text { Collaborative Project must be embedded in credit- } \\
\text { bearing course. }\end{array}$ & 2 sections of Thermodynamics I (ME 236) \\
\hline $\begin{array}{l}\text { CP must count for at least 20\% of final grade in the } \\
\text { course. }\end{array}$ & Worth 20\% of final grade \\
\hline $\begin{array}{l}\text { Student teams should be presented with a real-world } \\
\text { problem. }\end{array}$ & NAE Grand Challenge: "Provide Access to Clean Water" \\
\hline $\begin{array}{l}\text { Students on a team must be required to evaluate each } \\
\text { other's performance as team members. }\end{array}$ & $\begin{array}{l}\text { Web-tool: Comprehensive Assessment of Team-Member } \\
\text { Effectiveness (CATME) }\end{array}$ \\
\hline $\begin{array}{l}\text { The project must be presented in some way, either } \\
\text { within the course or in some public forum. }\end{array}$ & $\begin{array}{l}3 \text { in-class presentations per team; additionally, some } \\
\text { projects accepted for University Colloquium }\end{array}$ \\
\hline
\end{tabular}

In line with the aforementioned criteria and information, a project description was developed. The $\mathrm{CP}$ was introduced in the first week of class. It required student teams to develop engineering solutions within thermo-fluids to address one of the NAE Grand Challenges: "Provide Access to Clean Water". Toward this goal, students were required to (1) work collaboratively on the project (inside and outside of class) in groups of three to four; (2) propose an engineering design for a novel decentralized water treatment device; (3) utilize concepts learned in thermodynamics as a basis for design, analysis, and improvement of the proposed device; (4) conduct thermodynamic analysis on device as part of design proposal; (5) evaluate each other's performance as team members, utilizing Comprehensive Assessment of Team-Member Effectiveness (CATME) [4]; (6) report on project progress throughout the course, including a final report and presentation; (7) model their devices using commercial software tools; (8) develop a device close to the size of a dishwasher or refrigerator; (9) ensure device is capable of treating water up to $1 \mathrm{~L} / \mathrm{min}$; (10) use engineering analysis and reasoning to support any deviations from design constraints (8 and 9); (11) be prepared, that certain projects may be selected for application to the Undergraduate Research \& Creativity Colloquium.

In regard to the peer evaluation component of this project by students, CATME, had been used to facilitate better management of student teams [4]. This on-line teamwork learning and team management system [4] enabled team selection and peer-evaluations with Team-Maker [4, 5] and Peer Evaluation [4, 6, 7] tools, respectively. The use of CATME was adapted to help strategically form the best teams, as quickly as possible, saving time and effort, as the team 
selection process was automated (although still subject to the lead instructor's final approval). CATME quickly allowed for strategic grouping of students based on various factors with respect to similarity or complimentary styles. Factors included contrasting their typical approach to tasks (e.g., detail-oriented, big-picture oriented); or what day/time of the week they were available to meet up outside of class, e.g. commuters who were against meeting on weekends might be grouped with others that stayed on campus but preferred meeting on evenings after class.

A modeling and simulation component was implemented along with the CP. The choice of software (COMSOL) has been validated by a number of pedagogical studies [8,9]. The most common reported threads are improved teaching effectiveness and enhancement of student learning along with other by-products such as easy visualization of difficult theoretical concepts, exposure to simulation methodology, and satisfaction with the overall experience. The simulation component of the present study continues and builds on previous efforts which embedded the use of simulations at the junior level and above [3, 8, 9]. However, this is the first time that simulation-based assignments were implemented this early in the curriculum at our institution. Such efforts have however been reported in literature [10], indicating similar goals of helping to enhance student learning; linking theory with real-world applications, and helping to develop career-ready students prepared for job market requirements when they graduate. That study described implementation of two energy-related student projects using COMSOL and mentioned that assessment of students' satisfaction with the experience based on survey data was overall positive, but survey data was not included [10].

Our project incorporated three scaffolded and contextualized simulations that develop: (a) technical competency in modeling, (b) deeper understanding of thermo-fluids by solving realistic technological problems, and (c) technical report writing skills. Some aspects of each simulation assignment were directly related to the course work, while others provided a link between thermodynamic analysis and its applications in follow up thermo-fluid courses. While the assignments introduced students to the powerful software, its use in the final project was not required, as students' level of skill based on practice with only a few modules, might be limited, and also tempered by the actual capabilities of the software.

\section{Implementation of the Collaborative Project}

The $\mathrm{CP}$ accounted for $20 \%$ of the final grade in the course. Project requirements were communicated to students early on in the semester and any additional details were provided as necessary. Major milestones are shown in Table 3.Three iterations of reporting, modeling assignments, in-class presentations, and peer surveys were completed, with the final iteration being weighted higher than the previous ones. Each milestone required some form of electronic submission on previously scheduled dates/times. These electronic submissions were facilitated using CATME or Blackboard®, an online learning management system (LMS). Iterations gave students a chance to receive feedback and consistently improve their projects to a level commensurate with their learning. 
TABLE 3

COLlaborative ProjeCt MILESTONES.

\begin{tabular}{|c|c|c|c|c|c|}
\hline \multirow{2}{*}{$\begin{array}{c}\text { ITERATION } \\
0\end{array}$} & \multicolumn{2}{|r|}{ MiLeSTONES } & \multirow{2}{*}{$\begin{array}{l}\text { SUBMITTAL METHOD } \\
\text { CATME }\end{array}$} & \multirow{2}{*}{$\begin{array}{c}\text { PoINTS } \\
10\end{array}$} & \multirow{2}{*}{$\begin{array}{c}\text { GRADE } \\
(\%) \\
1\end{array}$} \\
\hline & 1 & Survey for Formation of Teams & & & \\
\hline \multirow{4}{*}{1} & 2 & Report \# 1 & Blackboard & 20 & \multirow{4}{*}{5} \\
\hline & 3 & Simulation Assignment \# 1 & Blackboard & 10 & \\
\hline & 4 & Presentation \# 1 & Blackboard/In-class & 10 & \\
\hline & 5 & Peer Survey \# 1 & CATME & 10 & \\
\hline \multirow{4}{*}{2} & 6 & Report \# 2 & Blackboard & 20 & \multirow{4}{*}{6} \\
\hline & 7 & Simulation Assignment \# 2 & Blackboard & 10 & \\
\hline & 8 & Presentation \# 2 & Blackboard/In-class & 20 & \\
\hline & 9 & Peer Survey \# 2 & CATME & 10 & \\
\hline \multirow{4}{*}{3} & 10 & Report \# 3 & Blackboard & 20 & \multirow{4}{*}{8} \\
\hline & 11 & Simulation Assignment \# 3 & Blackboard & 10 & \\
\hline & 12 & Presentation \# 3 & Blackboard/In-class & 40 & \\
\hline & 13 & Peer Survey \# 3 & CATME & 10 & \\
\hline & & & Total: & 200 & 20 \\
\hline
\end{tabular}

With "Clean Water" as a central theme, and consistent instructor feedback, students had to revisit their designs with additional analysis, as more theory was covered. For example, in the beginning, much of students' analysis included determination of properties and states required to "clean" the water, and consideration of designs/devices/methods that could be developed to facilitate these efforts, including types of energy sources that could be used. Much of the second iteration consisted of clearly discerning and applying appropriate forms of the first law of thermodynamics, with supporting equations and assumptions. The third iteration included more refined first law analysis, and second law considerations with students calculating entropy generation for their devices. Throughout each iteration, students were to report and justify an updated energy cost per liter of clean water produced, culminating in an overall value for their designs, to be described in a final presentation.

The simulation assignments, reports and peer surveys were consistently worth the same amount of points for each iteration, while the presentation was assigned an increasingly larger value. Consequently, students had ample time for improvement and feedback before making a final presentation. Additionally, after the first iteration, some students prepared an abstract for submittal at the Undergraduate Research \& Creativity Colloquium, separate from the course requirements. The accepted projects were presented at the Colloquium shortly after iteration \# 2 , again giving students an opportunity to make improvements and receive feedback. This schedule and general approach worked well, and each milestone is shown in Table 3.

CATME was operated in concert with Blackboard ${ }^{\circledR}$ (as a link from the courses' Blackboard® pages). The initial process of helping students acclimate to the CATME website was straightforward, as CATME provides a playlist of short video clips on YouTube (one to 
three minutes each), which explain how to use the system. Students were instructed to access the first five instructional videos to successfully log into their respective accounts and complete requested surveys by due dates/times. Once students had gained access to their respective accounts, the first survey they completed was for "Formation of Teams". The teams generated by the system helped guide the process of team selection by the instructor, and in most cases were completely adapted. Teams were seamlessly selected within a week. CATME also supported every iteration of the project, with peer evaluations being required after each submittal of reports, presentations and simulation assignments.

The three modeling and simulation assignments were: (1) Heat Radiation $1 \mathrm{~d}$; (2) Water Purification Reactor, and (3) Free Convection in a Water Glass. These were assigned for out-ofclassroom individual work. The objective in each was to produce a working COMSOL file and associated technical report for upload to the Blackboard®. At the beginning of the semester, instructions were given as to how to: access software either in the computer laboratory or on a personal computer; download step-by-step tutorials; create mph files and brief technical report; and upload documentation to Blackboard $®$. Each simulation topic was also addressed in class as appropriate. For example, the Heat Radiation simulation was tied to the discussion of surface energy balances. Work on simulation assignments that were cutting across different disciplines, necessitated going beyond the boundaries of thermodynamic analysis. The simulation of free convection in a water glass prompted the discussion on the estimate of the time it could take for the water to cool or warm and highlighted the concept of thermal equilibrium. Students were encouraged to use COMSOL for their Grand Challenge designs, although this was not required. In summary, simulations provided a foundation for students' further use of COMSOL software in subsequent projects and classes.

\section{Assessment of Collaborative Project and impact across courses}

Assessments reported here were based on student (1) work; (2) peer evaluations using CATME; (3) surveys during the CP experience; and (4) surveys in post-requisite courses. The comparison of these assessments provides cross-sectional and semi-longitudinal results. Not explicitly indicated here are other forms of formative and summative assessment including: retention; grades; teaching evaluations; student and professor reflections.

As students worked to complete the milestones previously highlighted in Table 3, the completed assignments were assessed by the instructor in a timely manner, and numerous opportunities were given for students to receive verbal and written feedback, inside and outside of class. In most cases students' work indicated increasing understanding of thermodynamics, enhanced capabilities of utilizing engineering software in a project environment, and overall higher quality analysis and application of engineering principles. While writing samples are not included here, select examples of student computer-aided modeling and simulation work is shown in Figs. 1-2. 


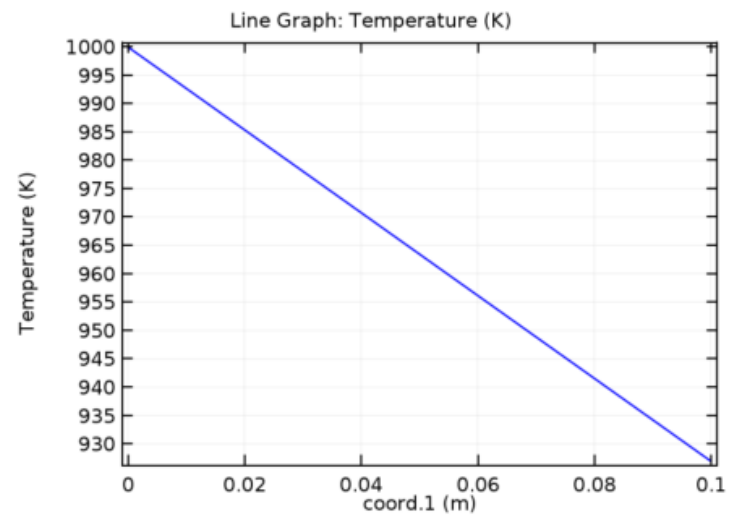

(a)

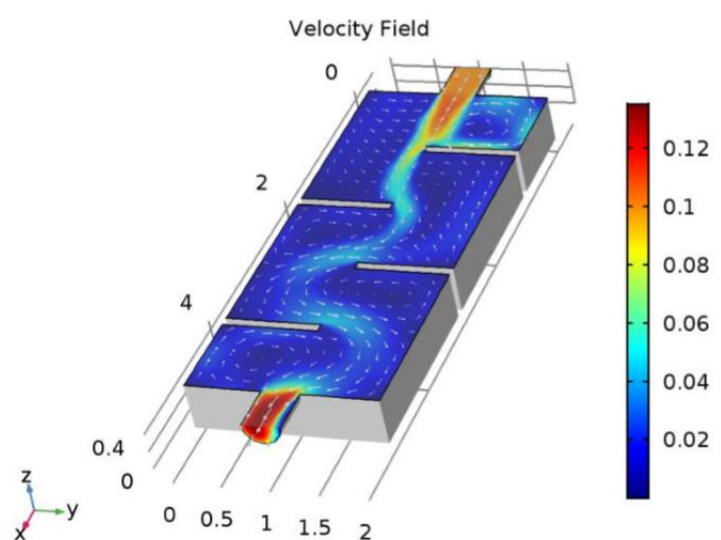

(b)

Fig. 1: Student work using COMSOL Multiphysics ${ }^{\circledR}$ software: (a) Assignment \# 1: "1-d Heat Radiation". (b) Assignment \# 2: "Water Purification Reactor".

Work shown in Fig. 1 was generated using COMSOL for simulation assignment \# 1: "Heat Radiation $1 \mathrm{~d}$ "; and for simulation assignment \# 2: "Water Purification Reactor". Student work, included more than COMSOL-based assignments. Their design solution reports, on providing access to clean water included extensive thermodynamic analysis, and the use of CAD programs, typically encountered as part of undergraduate mechanical engineering experiences. Student work shown in Fig. 2 was generated using a CAD program and SolidWorks. These samples include a "2D Model of Desalination Design", submitted for Report \# 3; and a "cooling fan" that students "initially intended to use to cool the condenser"; they further stated that the fan was to be "powered by the work output from the turbine". Lastly, Fig. 2 contains a sample of students' "SolidWorks drawing of desalination device," submitted for Report/ Presentation \# 3.

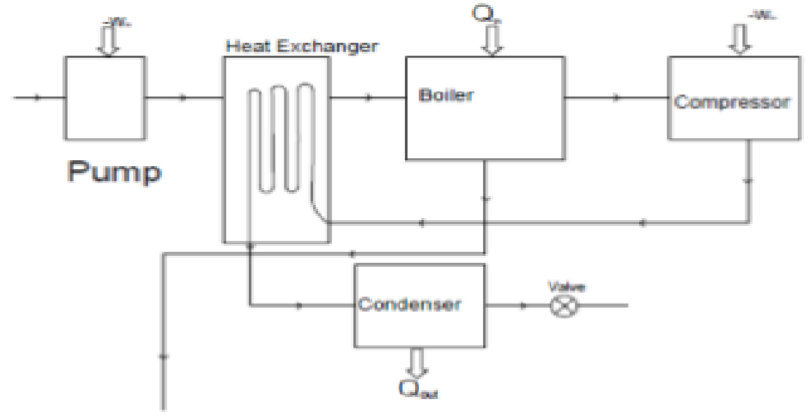

(a)

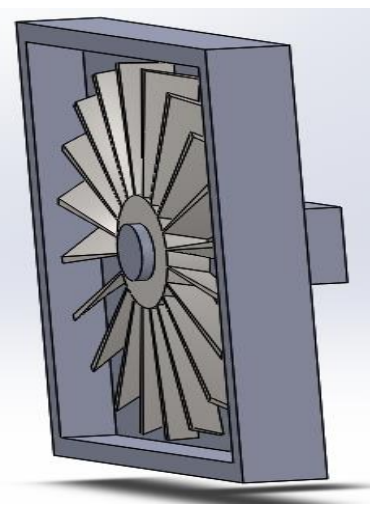

(b)

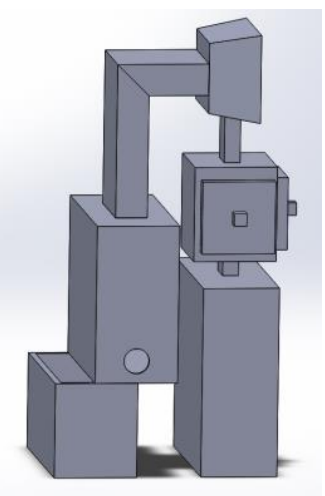

(c)

Fig. 2: CAD and SolidWorks samples of student work, including (a) "2D Model of Desalination Design"; (b) fan (c) "desalination device." 
As students assessed the members in their groups using CATME, the instructor got to see data that indicated if each member was assessed at a level on par, below or above the team average. In addition to the numerical data, there were situations where certain messages would accompany the team's assessment. While most teams' assessments appeared without any additional CATME-generated notes, there were cases where notes and associated warning messages were shown. These were very helpful to the instructor in managing what was actually happening within the teams. Fig. 3 shows an example of what the instructor might see when viewing CATME-generated results as per student peer evaluations. Fig. 3 (b) illustrates the view when the top section in Fig. 3 (a) is scrolled over with a computer mouse.

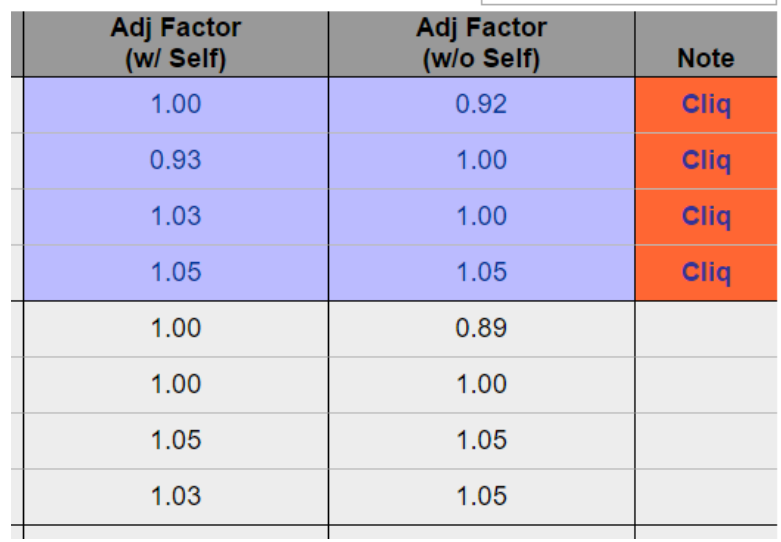

(a)

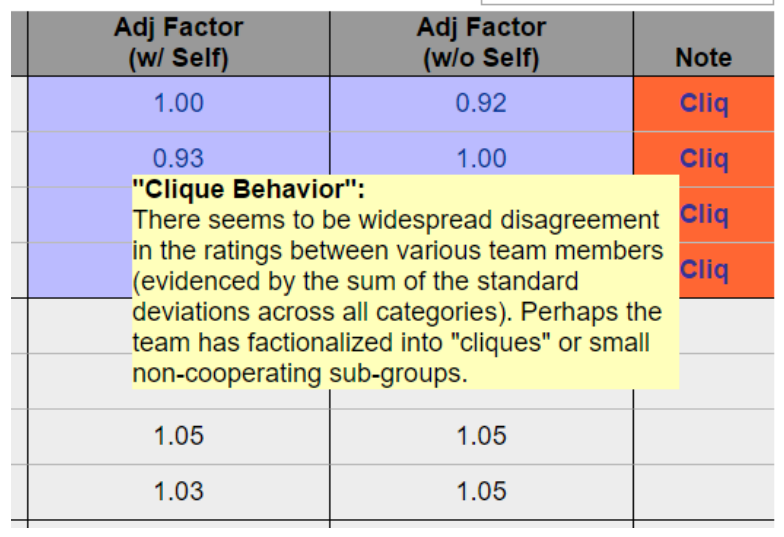

(b)

Fig. 3: Instructor views of select CATME-generated results as per student peer evaluations. (a) team member ratings; and (b) team member ratings with accompanying note

The top four rows of numerical data correspond to one of the student teams in a section of the course. The bottom four rows show numerical results for a different team. To the surprise of the instructor, what was apparent from observations and interactions with the highlighted team (at the top of Fig. 3), was evidenced quantitatively and qualitatively by the information in this figure. This assessment from CATME matched. Constructive student interaction is one of the key components of the HIP of CP, and while typical challenges are to be overcome by any team, the CATME feedback provided can help inform instructor management and guidance of the teams. It should be noted that, as per in-person feedback, and CATME feedback, it was apparent that most teams were able to work well together, such as the group at the bottom of Fig. 3 . However, a group like the one indicated at the top of Fig. 3 could be communicated with in more detail by the instructor as appropriate, and further managed (e.g. encouraged, reorganized, or disbanded, etc.). That was successfully done for the group referenced. In consideration of future use it should be noted that CATME started to charge a small fee right after the semester had culminated. 
In addition to assessments of students through review of their submitted work, and peer evaluations, the overall experience was assessed through surveys. Before presenting the results of the data included in this study, Fig. 4 contains a schematic picture of the order and specific course in which each survey was administered. An initial instructor-generated survey was administered once during the $\mathrm{CP}$ experience in the thermodynamics, ME 236 course. This survey would allow the instructor to get feedback on various elements of the implementation of the HIP. Subsequently, in two post-requisite courses (Thermodynamics II, ME 337 and Fluid Mechanics, ME 340), instructor-driven surveys were also administered, to get feedback on student perceptions of various aspects of each class, toward the goal of further course development. This data was de-identified and is presented in aggregate. The aggregate designations of "CP Student" and "Non-CP student" were mined from the data based on student individual responses to questions which most clearly asked them if they were part of the $\mathrm{CP}$. This paper provides information on the impact of the $\mathrm{CP}$ across courses, allowing for insight to be gained on student experiences within the major.
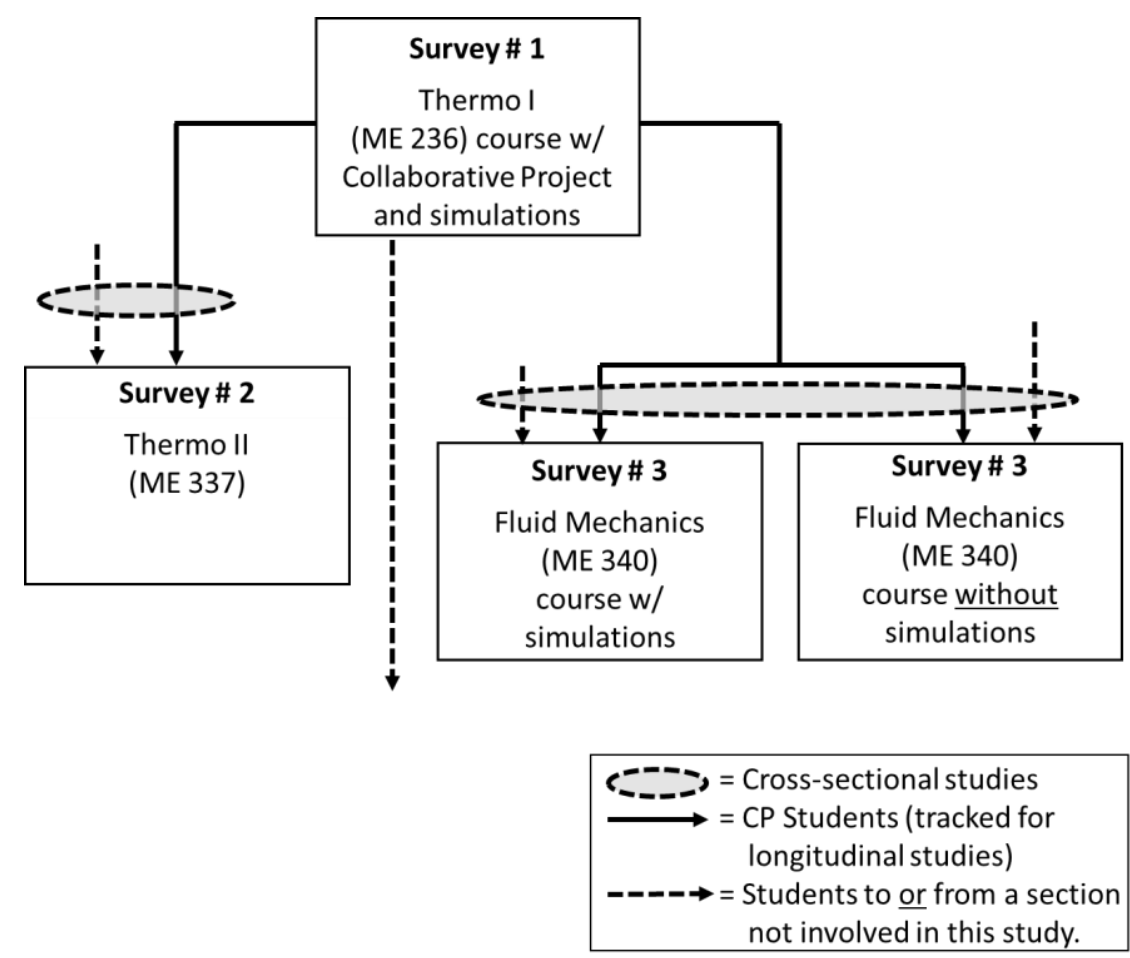

Fig. 4. Surveys included in this study.

Survey \# 1 was administered at the end of the CP experience in ME 236. These surveys consisted of 49 statements, for which each student was asked to rate their level of agreement using a five-point Likert scale with the following designations: (1) Strongly Disagree; (2) Disagree; (3) Somewhat agree; (4) Agree; and (5) Strongly agree. Twenty students completed the survey. All students provided answers to each of the 49 statements. Overall, the responses were 
positive about the project. Table 4 focuses on those results that elicited the strongest responses, i.e., survey statements for which the largest number of students most strongly agreed (an average $>4$ ); and for which the largest number of students most strongly disagreed (an average $<3$ ). Results in Table 4 indicate students' perceptions of the CP experience were overall favorable. These perceptions included: being happy that the $\mathrm{CP}$ presented them with a real-world problem to solve; being happy that they and their team members had to evaluate each other's performance as team members; the overall feeling that they used thermodynamics to design a real-world engineering system; and not only that they understood thermodynamics, but they understood it better as a result of the $\mathrm{CP}$.

TABLE 4

ME 236 SURVEY RESULTS

\begin{tabular}{|l|l|}
\hline Statements & AVG \\
\hline $\begin{array}{l}\text { A Collaborative Project was a part of my thermodynamics I (ME 236) course this } \\
\text { Spring } 2017 \text { semester. }\end{array}$ & 4.65 \\
\hline I am happy that the Collaborative Project was worth 20\% (or more) of my final grade. & 4 \\
\hline I wish the Collaborative Project was worth more than 20\% of my final grade. & 2.9 \\
\hline $\begin{array}{l}\text { I am happy that the Collaborative Project presented me with a real-world problem to } \\
\text { solve. }\end{array}$ & 4.4 \\
\hline This Collaborative Project added to my understanding of thermodynamics. & 4.25 \\
\hline $\begin{array}{l}\text { I am happy with the topic of this Collaborative Project: "Provide Access to Clean } \\
\text { Water". }\end{array}$ & 4.15 \\
\hline $\begin{array}{l}\text { I am happy that my team members and I had to evaluate each other's performance as } \\
\text { team members (whether or not I believe using CATME was the right method). }\end{array}$ & 4.35 \\
\hline $\begin{array}{l}\text { I utilized concepts learned in ME 236 as a basis for design, analysis, and improvement, } \\
\text { of the proposed device. }\end{array}$ & 4.25 \\
\hline $\begin{array}{l}\text { I developed my modeling abilities using commercial software tool, COMSOL, and I feel } \\
\text { that I may now use this software on my own, for other engineering projects. }\end{array}$ & 2.9 \\
\hline I used Thermodynamics to design a real-world engineering system. & 4.55 \\
\hline I understand thermodynamics better as a result of the Collaborative Project & 4.25 \\
\hline I understand thermodynamics. & 4.25 \\
\hline I enjoyed thermodynamics this semester & 4.2 \\
\hline $\begin{array}{l}\text { I built professional camaraderie with some of my engineering classmates IN } \\
\text { Thermodynamics I (ME 236). }\end{array}$ & 4 \\
\hline $\begin{array}{l}\text { I am more comfortable endeavoring to solve complex and real-world problems as a } \\
\text { result of this Collaborative Project. }\end{array}$ & 4.25 \\
\hline $\begin{array}{l}\text { I actively participated in in-class discussions related to Thermodynamics and Providing } \\
\text { Access to Clean Water. }\end{array}$ & 4.05 \\
\hline
\end{tabular}


In the semester following implementation of the CP, Survey \# 2 was administered at the beginning of one section of a post-requisite course, Thermodynamics II (ME 337). The students in this ME 337 course consisted of those that were previously part of the CP experience in ME 236. Others in ME 337, either completed thermodynamics in the previous semester at the authors' institution; had it in a different semester at the authors' institution; or had it at a different university. The survey results given in ME 337 consisted of responses from all 19 students in this ME 337 section, for each of 30 statements (except there was one statement in which only 18 of the 19 students provided answers). Select results of these surveys are represented in two ways: as a cross-sectional study (Fig. 5), with ME 337 responses segmented into CP vs. Non-CP Students vs. ALL Students in that section of ME 337; and as a longitudinal study (Table 5), where results of CP-Students in the ME 337 Survey are contrasted with ME 236 $\mathrm{CP}$ student responses. For Fig. 5, the designation of whether students were deemed "CP

Students" or "Non-CP Students was made based on students in ME 337 that indicated whether or not they had a CP in their ME 236 course. Hence, student responses that where $\geq 3$ for Statement \# 1, were deemed "CP Students". 


\section{a) Survey \# 2 - ME 337}

As part of my Thermodynamics (ME 236) course, I had a "Collaborative Project", which required me to work in a group with some of my classmates over the duration of the semester to complete an engineering design project.

I understand thermodynamics.

I understood Thermodynamics I (ME 236)

I am excited to learn more about thermodynamics in the Thermodynamics II (ME 337) course.

I would be excited to do undergraduate research, if presented an opportunity.

I would be excited to do undergraduate research related to thermodynamics, if presented an opportunity.

I like the engineering topic: "Provide Access to Clean Water".

I have used the commercial software tool, "COMSOL" before.

I have used thermodynamics to design a real-world engineering system.

I built professional camaraderie with some of my engineering classmates IN Thermodynamics I (ME 236)

I participated in my Thermodynamics I (ME 236) class more than I typically would in my engineering classes.

$$
\text { nost }
$$

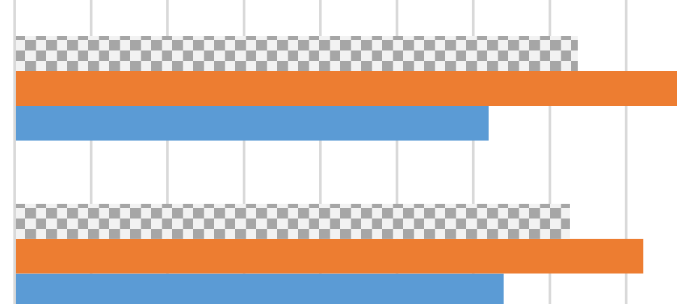

bis

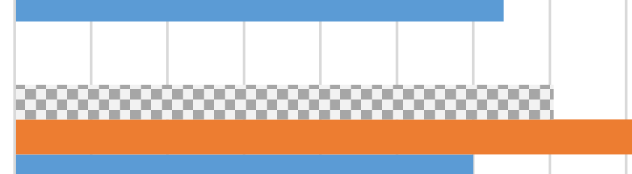

\section{past}
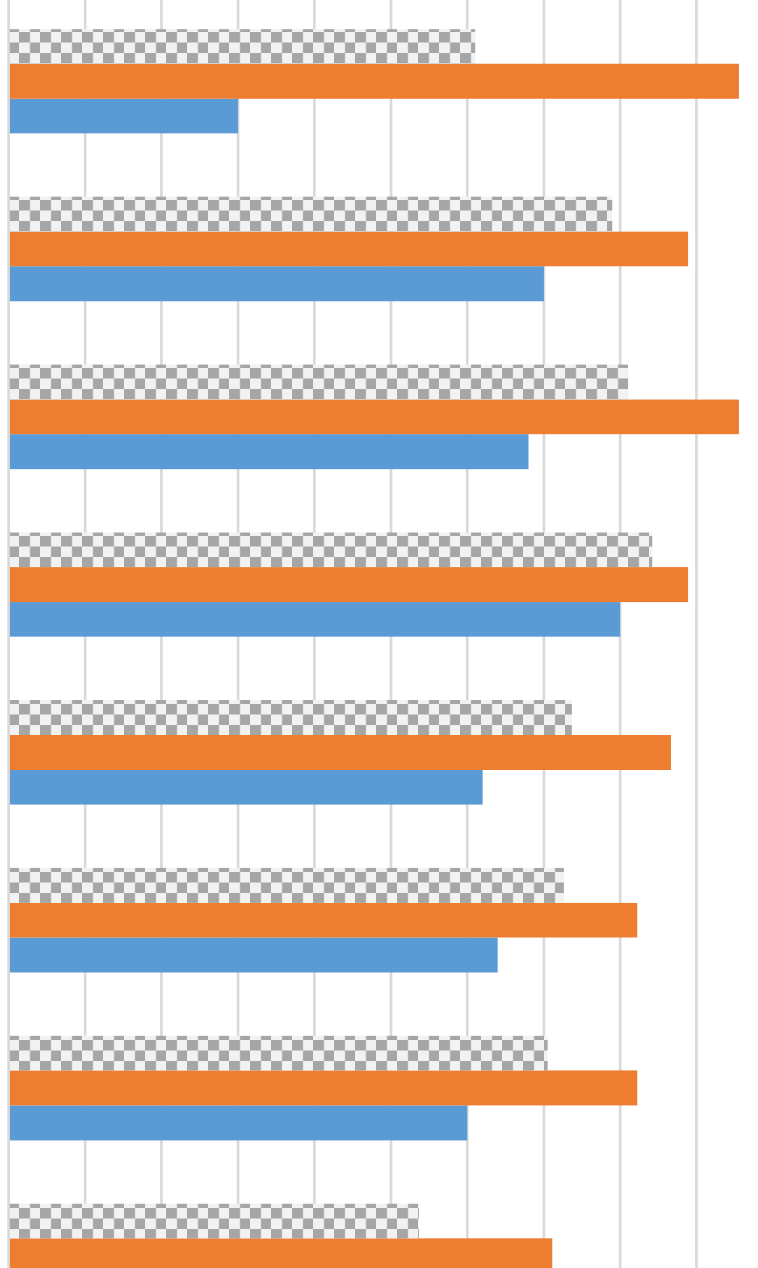

\section{Pars.}
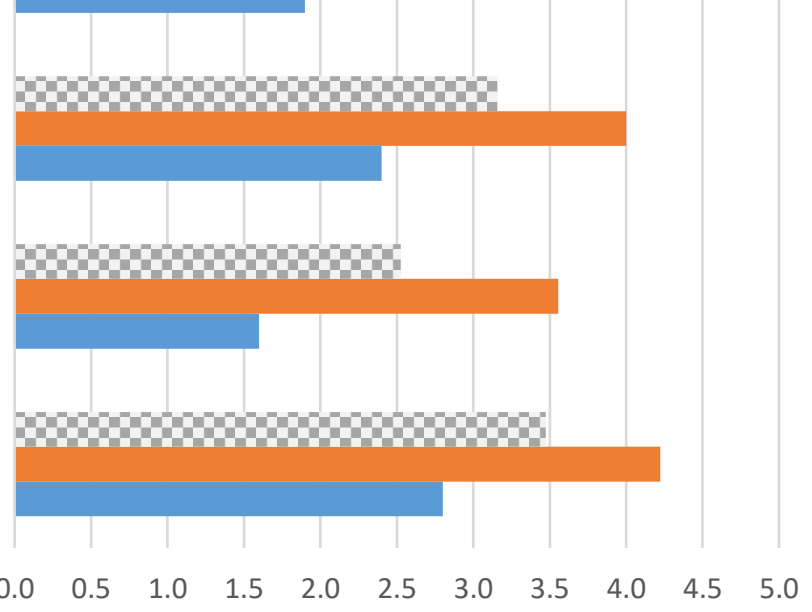

DE 337 - ALL Students

- ME 337 - CP Students

Fig. 5: Cross-sectional results of Survey \# 2 - ME 337 
A total of $47.37 \%$ of students responded affirmatively that they agreed that as part of their thermodynamics (ME 236) course, they had a CP, which required them to work in a group with some of their classmates over the duration of the semester to complete an engineering design project. It should be noted that the instructor confirms based on the roster that $47.37 \%$ of the students in the ME 337 course were indeed previously in the ME 236 course and exposed to the $\mathrm{CP}$. While the exact matching of these values could be taken as an indication of students understanding of the survey questions and subsequent honest answers, it is proposed that an uncertainty of $\pm 2 / 19( \pm 10.53 \%)$ could be assigned to all data results, to account for if a couple students provided inaccurate responses, due to various reasons including potential lack of clarity and subsequent misunderstanding of the survey questions; or rushing in completing the survey. With these factors in mind, a cross-sectional study is best satisfied by comparison of the CP vs. Non CP students' responses in Fig. 5.

Cross-sectional results in Fig. 5, indicated that CP students' level of agreement was higher than non-CP students in regard to the perception that they: understood, enjoyed, and were excited to learn more about thermodynamics in the Thermodynamics II (ME 337) course. They also were more likely to feel that they had used the commercial software tool, COMSOL before, and would like to use it again; and that they had built professional camaraderie with some of their engineering classmates in Thermodynamics I (ME 236). Where CP students' level of agreement was lower than Non-CP students, was in regard to the perception that they would be excited to do an engineering internship, related to thermodynamics.

In addition to cross-sectional results, results of the ME 337 survey (shown in Fig. 5) can be compared to the survey results obtained in ME 236, in such a way that a longitudinal study, can be represented as part of this assessment. This information has been compiled into Tables 5 to clearly show comparisons of select statements by CP students from Survey \# 1 (ME 236) and Survey \# 2 (ME 337). These statements are in regard to various aspect of the experiences of CP students, from their understanding of thermodynamics; affinity for the topic "Provide Access to Clean Water"; interest in undergraduate research; and abilities in using engineering modeling and simulation software such as COMSOL. The comparison of these responses represents semilongitudinal results, as CP students' responses are indicated over a time period of $\sim 5$ months, from a spring semester to the following fall semester.

Semi-longitudinal results in Table 5, indicate that students' level of agreement remained mostly consistent in regard to their perception that they: understand thermodynamics; enjoyed thermodynamics class (ME 236); were happy with the topic "Provide Access to Clean Water"; were more interested in participating in undergraduate research related to thermodynamics; built professional camaraderie with some of their engineering classmates in Thermodynamics I (ME 236) as a result of the CP. Semi-longitudinal results in Table 5, indicate that students' level of agreement degraded in regard to the statements: they understood thermodynamics better as a result of the CP. Results also indicate that students' level of agreement increased in regard to the statement: they participated in their Thermodynamics I (ME 236) class more than they typically would in their engineering classes. 
TABLE 5

SEMI-LONGITUDinAl RESUlTS - CP STUDENTS (IN ME 236), 4 MONTHS LATER (IN ME 337)

\begin{tabular}{|c|c|c|c|}
\hline ME 236 Survey & & ME 337 Survey & \\
\hline Statement & AVG & Statement & AVG \\
\hline I understand thermodynamics. & 4.25 & I understand thermodynamics. & 4.44 \\
\hline $\begin{array}{l}\text { I enjoyed thermodynamics this } \\
\text { semester }\end{array}$ & 4.2 & $\begin{array}{l}\text { I enjoyed Thermodynamics I (ME } \\
\text { 236). }\end{array}$ & 4.56 \\
\hline $\begin{array}{l}\text { I used Thermodynamics to design a } \\
\text { real-world engineering system. }\end{array}$ & 4.55 & $\begin{array}{l}\text { I have used thermodynamics to } \\
\text { design a real-world engineering } \\
\text { system. }\end{array}$ & 4.00 \\
\hline $\begin{array}{l}\text { I understand thermodynamics better } \\
\text { as a result of the Collaborative } \\
\text { Project. }\end{array}$ & 4.25 & $\begin{array}{l}\text { I understand thermodynamics better } \\
\text { as a result of a Collaborative Project } \\
\text { that was part of my } \\
\text { Thermodynamics I (ME 236) class. }\end{array}$ & 3.44 \\
\hline $\begin{array}{l}\text { I am happy with the topic of this } \\
\text { Collaborative Project: "Provide } \\
\text { Access to Clean Water". }\end{array}$ & 4.15 & $\begin{array}{l}\text { I like the engineering topic: } \\
\text { "Provide Access to Clean Water". }\end{array}$ & 4.11 \\
\hline $\begin{array}{l}\text { I am more interested in participating } \\
\text { in undergraduate research related to } \\
\text { Thermodynamics, as a result of the } \\
\text { CP. }\end{array}$ & 3.75 & $\begin{array}{l}\text { I would be excited to do } \\
\text { undergraduate research related to } \\
\text { thermodynamics, if presented an } \\
\text { opportunity. }\end{array}$ & 4.11 \\
\hline $\begin{array}{l}\text { I wish I used COMSOL more in this } \\
\text { class. }\end{array}$ & 3.2 & $\begin{array}{l}\text { I have used the commercial software } \\
\text { tool, "COMSOL" before, and I } \\
\text { would like to use it again. }\end{array}$ & 2.89 \\
\hline $\begin{array}{l}\text { I built professional camaraderie with } \\
\text { some of my engineering classmates } \\
\text { IN Thermodynamics I (ME 236) AS } \\
\text { A RESULT OF THE CP }\end{array}$ & 3.65 & $\begin{array}{l}\text { I built professional camaraderie with } \\
\text { some of my engineering classmates } \\
\text { IN Thermodynamics I (ME 236) AS } \\
\text { A RESULT OF CP. }\end{array}$ & 3.56 \\
\hline $\begin{array}{l}\text { I participated in thermodynamics } \\
\text { class more this semester than I } \\
\text { typically would. }\end{array}$ & 3.75 & $\begin{array}{l}\text { I participated in my } \\
\text { Thermodynamics I (ME 236) class } \\
\text { more than I typically would in my } \\
\text { engineering classes. }\end{array}$ & 4.22 \\
\hline
\end{tabular}

Survey \# 3 was administered toward the end of two sections of a post-requisite course, Fluid Mechanics, ME 340. One section of the ME 340 course is here named "ME 340C" as it had a COMSOL component involved as part of the course. The other ME 340 section is here named "ME 340D" as it didn't have a COMSOL component. Each of these sections was comprised of some mixture of "CP Students" and "Non- CP Students". Hence comparison of student responses to Survey \# 3 can provide additional insight, especially in regard to their perceptions on modeling and simulation work implemented into the thermo-fluid courses. Further, lasting impact of the $\mathrm{CP}$ with the modeling component might be able to be further commented on. With this in mind, for select survey statements in Survey \# 3, Fig.6 provides a bar graph indicating average responses of the following sub-groups of students: (i) $340 \mathrm{C}$ - Non- 
CP Students; (ii) 340C - CP Students; (iii) 340C - ALL students; (iv) 340D - Non-CP Students; (v) 340D - CP Students; and (vi) 340D - ALL Students.

\section{Survey \# 3 - ME 340C and ME 340D}

I developed my modeling abilities using commercial software tool, "COMSOL".

I would be happy to endeavor further on my own to use modeling software such as "COMSOL", as part of a future engineering design experience (such as Capstone Senior Design Project, undergraduate research, an internship, or a job).

I like thermo-fluids courses in engineering such as thermodynamics, fluid mechanics, and heat transfer.

I am excited for opportunities to use modeling software (such as "COMSOL") in future engineering courses.

I developed my modeling abilities using commercial software tool, "COMSOL", and I feel that I may now use this software on my own, for other engineering projects.

I wish I used "COMSOL" more in this class.

I have used the commercial software tool, "COMSOL" before.

Utilizing modeling software has made me more interested in learning about the subject matter in this course.

As part of my Thermodynamics (ME 236) course, I had a "Collaborative Project", which required me to work in a group with some of my classmates over the duration of the semester to complete an engineering design project.

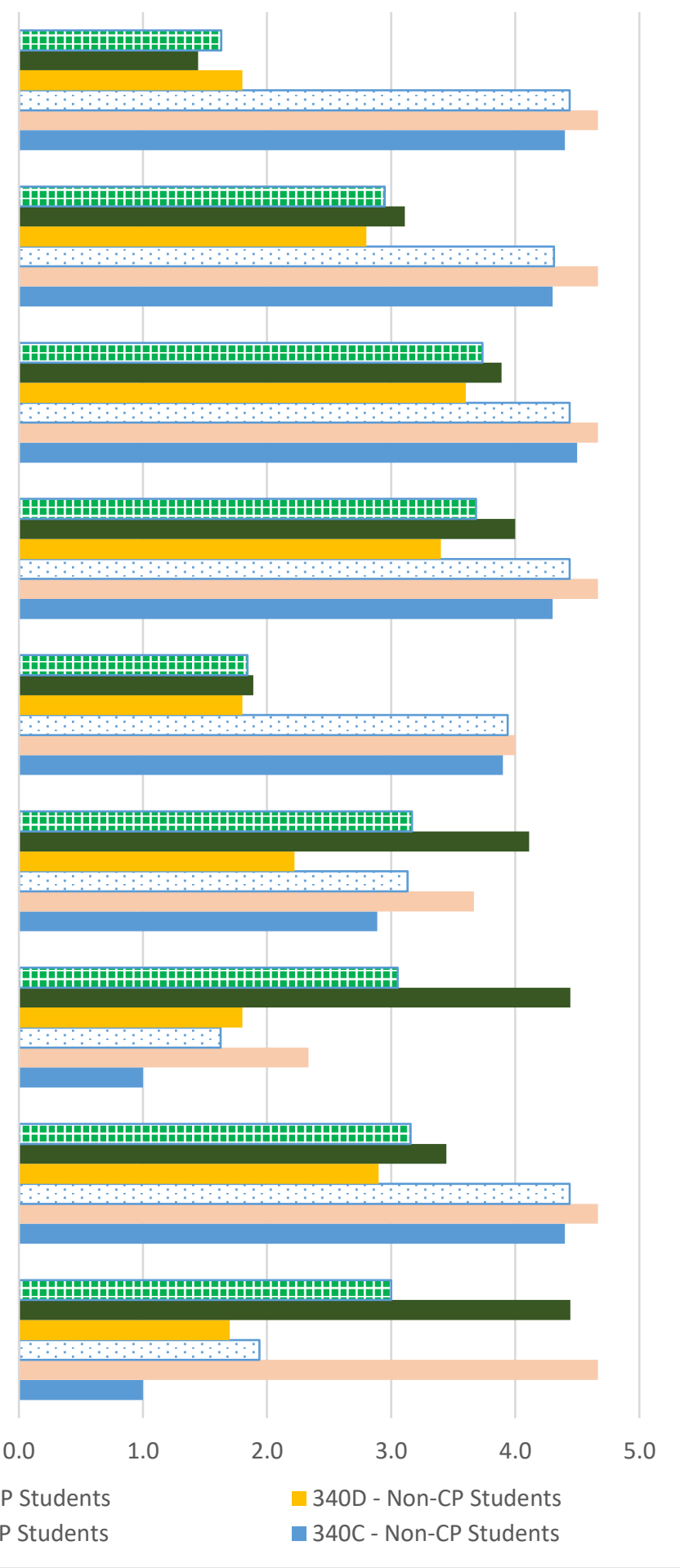

Fig. 6: Select cross-sectional results of Survey \# 3 - ME 340C and ME 340D 
"CP Students" were designated based on student responses that where $\geq 4$ for the last statement listed in Fig. 6, "As part of my Thermodynamics (ME 236) course... design project". This statement could have been posed as a yes or no question but it was kept in the Likert-scale format. Further, responses greater than 3 could have been used as it would have resulted in one extra student, but for this type of statement it was determined that those who were part of the CP project would more quickly and strongly indicate their prior participation, while a student reading who had some sort of project in a previous course (though not a HIP, CP) might be keen on selecting an answer of 3 (an in between kind of answer). In general, the results of Survey \# 3 also represent a cross-sectional study.

Various insights can be mined from the results of Survey \# 3, especially in regard to the use of software in thermo-fluid courses. Overall, ME 340C student responses about the modeling and simulation portion of their ME 340 course was positive, e.g., they indicated that utilizing modeling software has them more interested in learning about the subject matter in the Fluid Mechanics course. While a more full discussion of the implementation of modeling and simulation into thermo-fluids courses is a topic for another paper, there are some aspects of this endeavor, which offer insight into the impact of the $\mathrm{CP}$, and the associated modeling and simulation portion involved in this effort. In general for Survey \# 3, the largest differences were in responses to statements that asked about student's previous use of COMSOL Multiphysics®, as well as the statement, which asked if they had a CP as part of their thermodynamics course. As expected, CP students typically had stronger levels of agreement with such statements.

It should be noted that except for the statement about previous $\mathrm{CP}$ experience, the differences in CP vs Non-CP student responses were all within standard deviations of their respective student responses. Hence, the impact of exposure to the use of modeling and simulation assignments using COMSOL Multiphysics ${ }^{\circledR}$ as part of the CP in Thermodynamics I (ME 236) was not as evident based on survey results from the post-requisite course Fluid Mechanics (ME 340). In comparing Survey \# 3 student responses for ME 340C and ME 340D, and further comparing the responses of CP vs Non CP students for each respective section, there is some interesting insight suggested by the data. Survey \# 3 (ME 340) results generally indicated that students exposed to COMSOL software in their ME 340 class, had generally more positive responses about use of this software, although students in both the ME 340C and ME 340D class expressed similar levels of agreement that they wished they used it more in their ME 340 course. Interestingly, and potentially attributable to various reasons, students in the ME 340C class expressed a higher level of agreement that they liked thermo-fluids courses. Still, in regard to differences in CP students vs. Non-CP students in each section of ME 340, CP students in both sections expressed a higher level of agreement than Non-CP students, that they liked thermo-fluids courses in engineering such as Thermodynamics, Fluid mechanics, and Heat Transfer. 


\section{Conclusions}

A CP was implemented as a HIP, into sections of a sophomore level Thermodynamics I course in mechanical engineering. This $\mathrm{CP}$ required students to tackle the NAE grand challenge, "Provide Access to Clean Water", where they had to engage in a semester long team project which tasked them with designing a water treatment device on the basis of thermodynamic analysis. Additionally, this approach was implemented with a simulation component toward the goal of exposing students to the use of software as they make engineering design considerations on projects in and beyond the classroom.

Overall, this project was a success, as quantified by various factors, including those presented in a wide range of survey data, including those administered in ME 236 during the CP experience, as well as those given months later in post-requisites courses, ME 337 (Thermodynamics II), and ME 340 (Fluid Mechanics). Cross-sectional results from the ME 337 survey indicated that in general, students exposed to the $\mathrm{CP}$, typically had a higher level of agreement than non-CP students with a wide range of statements, including those related to understanding thermodynamics; excitement to do undergraduate research; interest in using COMSOL and feeling that they had built professional camaraderie with some of their engineering classmates in Thermodynamics I (ME 236). Semi-longitudinal results from the ME 337 Survey indicated that students' level of agreement with most survey statements in regard to thermodynamics, remained relatively consistent over time, including the statements that: they understood and enjoyed thermodynamics.

In regard to simulations, while most students felt that they developed their modeling and simulation abilities, and felt that if they had additional COMSOL modeling assignments in another class, they would be able to use this software effectively in the future, students only somewhat agreed that they would like to use this software again. Potential reasons for this is that only three modules were assigned; the simulation portion of the $\mathrm{CP}$ was not the main emphasis; and in general, learning new software can take more time and concerted effort. The experience of students who went on to courses in which they utilized their COMSOL Multiphysics ${ }^{\circledR}$ simulation skills within the next few semesters in thermo-fluid courses can be further studied to reveal deeper insights. Already reported in the present study was that CP students re-exposed to COMSOL in Fluid Mechanics in the following semester, consistently revealed more positive responses than non-CP students exposed to COMSOL, including the statement that, they wished they used COMSOL more in their class. They even revealed a stronger level agreement that they liked thermo-fluids courses in engineering.

Finally, it is concluded that the HIP reported here, which consisted of a CP effort with a modeling component, was an overall success. Future studies can include implementation of such a HIP with a larger modeling component, and subsequent assessment as appropriate. 


\section{References:}

[1] G. D. Kuh and AAC\&U. (2017, November 22). High-Impact Educational Practices, A Brief Overview. Association of American Colleges \& Universities (AAC\&U). Available: https://www.aacu.org/leap/hips

[2] C. M. Vest, "Context and challenge for twenty-first century engineering education," Journal of Engineering education, vol. 97, no. 3, pp. 235-236, 2008.

[3] T. Eppes, I. Milanovic, and K. Wright, "Applications and App Building in Hybrid Courses," International Journal of Online Engineering (iJOE), vol. Volume 13, no. Issue 11, 2017.

[4] CATME. (2017, November 22). Comprehensive Assessment of Team Member Effectiveness (CATME). Available: www.CATME.org

[5] R. A. Layton, M. L. Loughry, M. W. Ohland, and G. D. Ricco, "Design and Validation of a WebBased System for Assigning Members to Teams Using Instructor-Specified Criteria," Advances in Engineering Education, vol. 2, no. 1, p. n1, 2010.

[6] M. W. Ohland et al., "The comprehensive assessment of team member effectiveness: Development of a behaviorally anchored rating scale for self-and peer evaluation," Academy of Management Learning \& Education, vol. 11, no. 4, pp. 609-630, 2012.

[7] M. L. Loughry, M. W. Ohland, and D. DeWayne Moore, "Development of a theory-based assessment of team member effectiveness," Educational and Psychological Measurement, vol. 67, no. 3, pp. 505-524, 2007.

[8] I. Milanovic and T. Eppes, "Application building in undergraduate courses with a simulation component," in ASME 2016 Fluids Engineering Division Summer Meeting collocated with the ASME 2016 Heat Transfer Summer Conference and the ASME 2016 14th International Conference on Nanochannels, Microchannels, and Minichannels, 2016, pp. V002T01A003V002T01A003: American Society of Mechanical Engineers.

[9] I. Milanovic and T. Eppes, "Improving Student Readiness for Inquiry-Based Learning," in ASME/JSME/KSME 2015 Joint Fluids Engineering Conference, 2015, pp. V001T01A002V001T01A002: American Society of Mechanical Engineers.

[10] Y. Ngabonziza and H. Delcham, "The Enhancement of Students Learning Through COMSOL Simulation Projects." 